\title{
Review
}

\section{Risk factors and protective measures for healthcare worker infection during highly infectious viral respiratory epidemics: A systematic review and meta-analysis}

\author{
Chenchen Tian BHSc ${ }^{1}$ (1), Olivia Lovrics MSc ${ }^{2}$, Alon Vaisman MD MAS FRCPC ${ }^{3}$, Ki Jinn Chin MD FRCPC ${ }^{4}$, \\ George Tomlinson $\mathrm{PhD}^{5}$, Yung Lee $\mathrm{MD}^{6}$, Marina Englesakis MLIS ${ }^{7}$, Matteo Parotto MD $\mathrm{PhD}^{4,8}$ and \\ Mandeep Singh MBBS MD MSC FRCPC ${ }^{4,8}$ \\ ${ }^{1}$ Faculty of Medicine, University of Toronto, Toronto, Ontario, Canada, ${ }^{2}$ Faculty of Medicine, McMaster University, Hamilton, Ontario, Canada, ${ }^{3}$ Infection \\ Prevention and Control, University Health Network, Toronto, Ontario, Canada, ${ }^{4}$ Department of Anesthesia and Pain Management, University Health Network, \\ Toronto, Ontario, Canada, ${ }^{5}$ Department of Medicine, University Health Network, Toronto, Canada, ${ }^{6}$ Division of General Surgery, McMaster University, Hamilton, \\ Ontario, Canada, ${ }^{7}$ Library and Information Services, University Health Network, Toronto, Ontario, Canada and ${ }^{8}$ Department of Anesthesia and Pain Management, \\ Women's College Hospital, Toronto, Ontario, Canada
}

\section{Abstract}

Objective: To investigate risk factors for healthcare worker (HCW) infection in viral respiratory pandemics: severe acute respiratory coronavirus virus 2 (SARS-CoV-2), Middle East respiratory syndrome (MERS), SARS CoV-1, influenza A H1N1, influenza H5N1. To improve understanding of HCW risk management amid the COVID-19 pandemic.

Design: Systematic review and meta-analysis.

Methods: We searched MEDLINE, EMBASE, CINAHL, and Cochrane CENTRAL databases from conception until July 2020 for studies comparing infected HCWs (cases) and noninfected HCWs (controls) and risk factors for infection. Outcomes included HCW types, infection prevention practices, and medical procedures. Pooled effect estimates with pathogen-specific stratified meta-analysis and inverse variance meta-regression analysis were completed. We used the GRADE framework to rate certainty of evidence. (PROSPERO no. CRD42020176232, 6 April 2020.)

Results: In total, 54 comparative studies were included ( $\mathrm{n}=191,004 \mathrm{HCWs).} \mathrm{Compared} \mathrm{to} \mathrm{nonfrontline} \mathrm{HCWs,} \mathrm{frontline} \mathrm{HCWs} \mathrm{were} \mathrm{at}$ increased infection risk (OR, 1.66; 95\% CI, 1.24-2.22), and the risk was greater for HCWs involved in endotracheal intubations (risk difference, 35.2\%; 95\% CI, 21.4-47.9). Use of gloves, gown, surgical mask, N95 respirator, face protection, and infection training were each strongly protective against infection. Meta-regression showed reduced infection risk in frontline HCWs working in facilities with infection designated wards (OR, $-1.04 ; 95 \% \mathrm{CI},-1.53$ to $-0.33, P=.004)$ and performing aerosol-generating medical procedures in designated centers $(\mathrm{OR},-1.30$; $95 \% \mathrm{CI},-2.52$ to $-0.08 ; P=.037)$.

Conclusions: During highly infectious respiratory pandemics, widely available protective measures such as use of gloves, gowns, and face masks are strongly protective against infection and should be instituted, preferably in dedicated settings, to protect frontline HCW during waves of respiratory virus pandemics.

(Received 25 September 2020; accepted 2 December 2020; electronically published 25 January 2021)

The profound impact of the novel coronavirus (SARS-Cov-2) has been driven by the ease with which human-to-human transmission occurs, contributing to the rapid propagation of coronavirus disease 2019 (COVID-19). SARS-Cov-2 can be transmitted through cough or respiratory droplets, contact with infected bodily fluids, or less commonly, from contaminated surfaces. ${ }^{1,2}$

Author for correspondence: Mandeep Singh, E-mail: Mandeep.Singh@uhn.ca

Cite this article: Tian C, et al. (2022). Risk factors and protective measures for healthcare worker infection during highly infectious viral respiratory epidemics: A systematic review and meta-analysis. Infection Control \& Hospital Epidemiology, 43: 639-650, https://doi.org/10.1017/ice.2021.18
Healthcare workers (HCWs) are particularly vulnerable to SARS-CoV-2 infection and other emerging, highly infectious diseases due to close contact with infected patients and contaminated materials. ${ }^{3}$ Previous coronaviruses, such as severe acute respiratory syndrome coronavirus (SARS) and Middle East respiratory syndrome coronavirus (MERS), have demonstrated extensive transmission in healthcare settings even though they are relatively inefficient in transmission within the general community. ${ }^{4,5}$ As of July 14, 2020, data from Italy estimated that healthcare providers managing patients with COVID-19 account for $12 \%$ of cases. ${ }^{6}$ Factors believed to contribute to the rapid spread among 
healthcare workers include suboptimal infection control practices, performance of aerosol-generating medical procedures, and failure to continue adequate mask use in break rooms. ${ }^{7-9}$ The prevalence of infected HCWs also differs by hospital units, being highest in medical intensive care units and emergency departments. ${ }^{10}$

The preservation of health and wellness in HCWs is paramount because of their role in caring for critically ill patients as well as the need to prevent outbreaks in healthcare facilities. ${ }^{11}$ Currently, understanding of COVID-19 infection rates in HCWs and the risk factors predisposing to infection in pandemic settings is limited, and infection control guidelines across international organizations are inconsistent. ${ }^{12}$ Prior systematic reviews have focused on subsets of viral respiratory infections, but none have focused on risk factors for HCW infection in pandemic settings. A recent metaanalysis found protective effects of face masks, eye protection, and physical distancing in preventing virus transmission in both public and healthcare settings. ${ }^{13}$ Healthcare settings are unique in their challenges to financial and PPE resources, workforce availability, inherent fear, and anxiety among frontline staff, which are exacerbated during novel viral outbreaks. ${ }^{14}$ The current study provides a thorough review of occupational risk factors for infection in HCWs and protective measures necessary to mitigate risk in such rare and challenging times. Therefore, in this systematic review and meta-analysis, we aimed to identify risk factors for HCW infection during a WHO-classified epidemic of a highly infectious viral respiratory infection, comparable to COVID-19.

\section{Methods}

\section{Search strategy and selection criteria}

The study was prepared according to the Preferred Reporting Items for Systematic Review and Meta-Analysis (PRISMA) guidelines ${ }^{15}$ and was guided by specifications outlined in the Meta-analysis of Observational Studies (MOOSE) recommendations. ${ }^{16}$ The study was registered on PROSPERO (CRD42020176232) on April 6, 2020.

The search strategy was developed in consultation with a medical librarian and was conducted according to recommendations in the Cochrane Rapid Review guide. ${ }^{17}$ The searches were conducted in electronic databases MEDLINE, EMBASE, CINAHL, and Cochrane CENTRAL from database conception until July 6, 2020 (Appendix 1 online). We excluded case reports, case series, editorials, narrative reviews, consensus opinions, news articles, and letters to the editor. Searches were restricted to articles written in English and studies involving human subjects only.

Titles and abstracts were screened to identify potentially eligible studies, which subsequently underwent full-text review for study inclusion using predetermined inclusion and exclusion criteria. Literature screening and eligibility assessment was performed independently by 2 reviewers (C.T., O.L.) at all stages. Reasons for exclusion were documented at each stage. Data extraction was conducted independently by 2 authors (C.T., O.L.) using a standardized data extraction form. Opinions from senior authors were solicited to resolve any conflicts.

Studies were included if the study population was comprised of HCWs in a healthcare setting with pandemic respiratory disease with a similar outbreak and transmission dynamics (droplet size) to COVID-19, including MERS, SARS, H1N1, and H5N1. Studies describing nonrespiratory infectious diseases, infectious diseases not defined by the World Health Organization (WHO) as epidemic or pandemic (eg, seasonal influenza), and diseases occurring in nonhealthcare settings were excluded. HCWs were defined as all staff in a healthcare facility involved in the provision of care to patients, not only those directly providing patient care. ${ }^{18}$ Only comparative studies with a valid infected HCW (cases) group and a noninfected HCW (control) group were included. Therefore, studies that reported the prevalence of risk factors (described below) in both case and control groups were eligible for inclusion. We included observational studies (eg, cross-sectional, cohort, or case-control studies) and experimental studies (eg, randomized control trials [RCTs]).

\section{Outcomes of interest}

We sought to answer 3 knowledge questions: (1) Which types of HCWs and which medical departments are at increased risk of infection? (2) Which infection prevention and control practices are associated with protective effects for infection in HCWs? (3) Which exposures or procedures are associated with infection in HCWs? We collected data related to occupational risk factors that addressed these questions using 4 outcomes (categorical variables) in the case (infected HCWs) and control (non-infected HCWs) groups. (1) We collected data related to HCW occupation type as described previously. ${ }^{18}$ (2) We collected data related to work department (eg, ward, emergency [ER], intensive care unit [ICU]). Frontline HCW were defined as those with high occurrence of patient face-to-face contact, including ER staff, ICU staff, and HCW who responded affirmatively to having exposure with patients. We sought to determine whether the health facility was a designated treatment center or was unidentified as a designated center. (3) We collected data related to the following infection prevention and control practices (IPAC): personal protective equipment (PPE) use (eg, surgical mask, N95 respirator or equivalent, gowns, full-body protection, eye and face protection, gloves, proper donning and doffing techniques), hand hygiene, IPAC training, vaccination status, pharmaco-prophylaxis. (4) We collected data related to exposure and procedural risks, that is, exposures to infected patients and colleagues, contaminated materials, participation in intubation or other aerosol-generating medical procedures (AGMPs). ${ }^{19}$

\section{Data analysis}

All statistical analyses and the meta-analysis were performed on STATA version 15.1 software (StataCorp, College, TX) ${ }^{20}$ and Comprehensive Meta-Analysis version 3 software (Englewood, $\mathrm{NJ}){ }^{21}$ We performed meta-analyses using a DerSimonian and Laird random-effects model for continuous and dichotomous outcomes, wherever applicable. Pooled effect estimates were obtained by calculating the odds ratios (ORs) for dichotomous outcomes along with their respective $95 \%$ and $99 \%$ confidence intervals (CIs). A subgroup analysis was conducted for each infectious agent.

Inverse variance weighted meta-regression analysis was performed to investigate the association between study characteristics and relevant outcomes. We included categorical variables (eg, virus type, designated centre, IPAC training, and ICU status) in the meta-regression models, wherever applicable. The $\mathrm{R}^{2}$ statistic was used to measure the proportion of the variability in the outcome measure explained by the statistical model.

The quality of nonrandomized studies was assessed using the Newcastle-Ottawa scale (NOS) adapted to each study's design. ${ }^{22-24}$ Sensitivity analyses were conducted excluding studies with higher risk of bias. Heterogeneity between studies was assessed qualitatively and quantitatively using the Higgins $\mathrm{I}^{2}$ statistic. Publication bias was assessed using Egger regression and visual inspection of funnel plots. Evidence was evaluated according to the Grading of Recomm endations Assessment, Development, and Evaluation (GRADE) framework. ${ }^{25}$ 


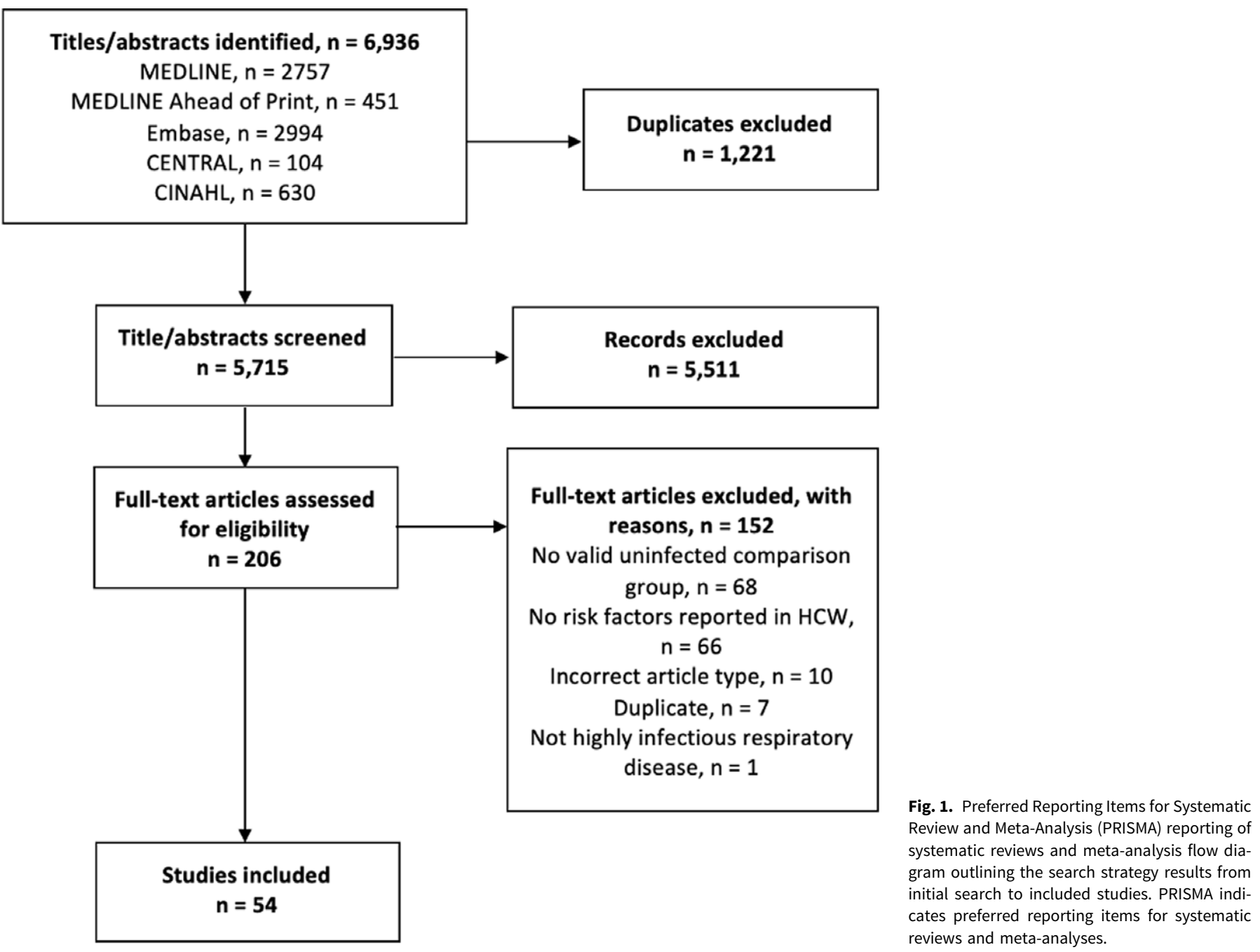

\section{Results}

After the removal of duplicated search results, 6,936 articles underwent title and abstract screening. Of these, 204 full-text articles were assessed for eligibility for inclusion. Overall, 54 studies were included for analysis (Fig. 1).

The included studies represented a total population of 191,004 healthcare workers and 7,375 cases of confirmed infection by the pathogen under study. All included studies were comparative and observational in nature, including 28 retrospective cohort studies, 10 case-control studies, 11 prospective cohort studies, and 5 cross-sectional studies, and the studies were conducted across 5 continents among 20 countries (Table 1). The infectious agents evaluated included COVID-19 (17 studies, $\mathrm{n}=152,019){ }^{26-42} \mathrm{H} 1 \mathrm{~N} 1$ (18 studies, $\mathrm{n}=26,349),{ }^{43-60}$ SARS ( 15 studies, $\left.\mathrm{n}=6,360\right),{ }^{61-75}$ MERS ( 3 studies, $\mathrm{n}=5,750),{ }^{76-78}$ and H5N1 (1 study, $\left.\mathrm{n}=526\right) .{ }^{79}$ No eligible RCTs were identified. The vast majority of studies ( 49 of 54 ; $90 \%$ ) used WHOdefined criteria for confirmation of cases (Table 1).

Study quality ranged from poor $(n=27)$, to fair $(n=2)$, to good $(\mathrm{n}=25)$ (Appendix 2 online). ${ }^{80}$ To adjust for study quality, sensitivity analyses including only studies with low risk of bias (NOS $\geq 7$ ) did not yield any significant change in effect estimates for outcomes. Evidence of publication bias from visual inspection of funnel plots and the Egger test was not strongly indicative (Table 2; Appendix 3 online).
Infection rates in frontline HCWs were analyzed from 32 studies $^{28,29,31,33,34,36,38,39,41,42,45-51,53,54,56,59,60,63-65,69-71,79,81-83}$ and were significantly higher in this group of HCWs compared to nonfrontline HCWs (OR, 1.66; 95\% CI, 1.24-2.22, $P=.001 ; 12.0 \%$ in frontline vs $4.4 \%$ non-frontline; low certainty) (Fig. 2; Table 2). Meta-regression analysis using random effects was performed by including covariates, wherever applicable. The overall risk of infection was higher among frontline workers $\left(2\right.$-sided $P=.039 ; \tau^{2}=.3435$; $\mathrm{R}^{2}=72 \%$ ). Furthermore, working within a designated center versus an unidentified center was protective (OR, $-1.04,95 \% \mathrm{CI},-1.53$ to $-0.33 ; P=.004$ ) (Table 1; Appendix 5, Fig. 1 online). Our model was unable to detect statistical difference in infection risk between the various virus types $(P=.566)$. Similarly, there was low certainty that the difference in overall infection rates between physicians and nurses was not statistically significant (Table 2; Appendix 4, Fig. 1 online). ${ }^{26,28,30-32,34-37,41,43-45,49-51,54-57,67,70,73-76,81,82,84}$

Compared to control (ie, no use of corresponding PPE item), use of gloves (16 studies) ${ }^{31,32,38,46,50,51,55,58,61,63,65,67,69,70,72,74}$, gowns (8 studies $)^{31,32,50,63,67,69,72,74}$, surgical masks (12 studies) ${ }^{38,49-51,55,58,67,70-73,75}$, N95 respirators (15 studies $)^{27,35,40,50,51,55,61,63,65,69-71,74,78,81}$, and face protection (11 studies) ${ }^{32,50,60,61,67-70,74,77,78}$ were associated with large reductions in the risk of infection (moderate certainty; Table 2; Appendix 4, Figs. 2-6 online). The definition of N95 respirator use varied greatly across studies. The 2 studies with the strongest effects for use of N95 respirators both investigated COVID-19, but they did 
Table 1. Study Characteristics

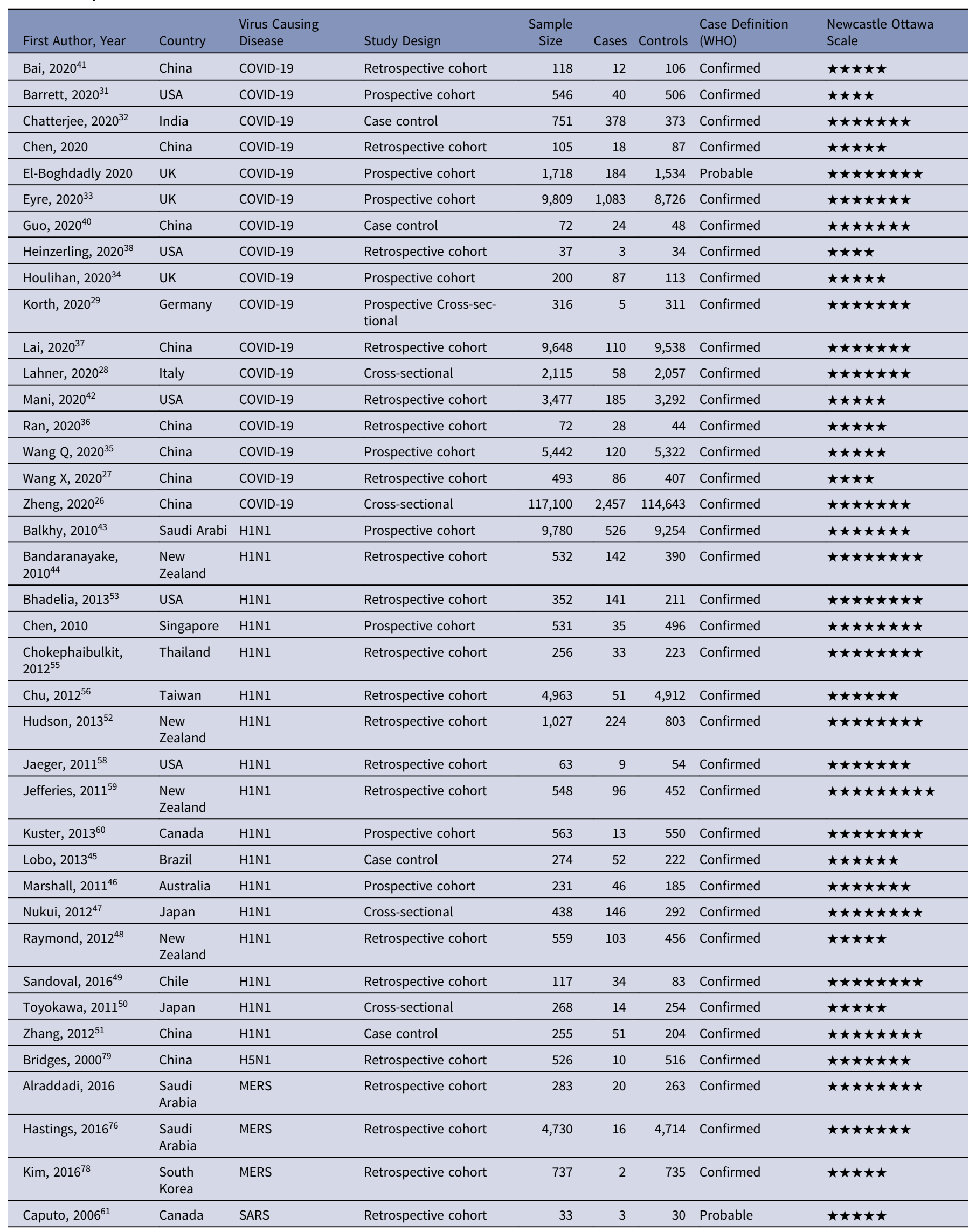


Table 1. (Continued)

\begin{tabular}{|c|c|c|c|c|c|c|c|c|}
\hline First Author, Year & Country & $\begin{array}{l}\text { Virus Causing } \\
\text { Disease }\end{array}$ & Study Design & $\begin{array}{l}\text { Sample } \\
\text { Size }\end{array}$ & Cases & Controls & $\begin{array}{l}\text { Case Definition } \\
(\mathrm{WHO})\end{array}$ & $\begin{array}{l}\text { Newcastle Ottawa } \\
\text { Scale }\end{array}$ \\
\hline Chen MIC, $2006^{82}$ & Taiwan & SARS & Retrospective cohort & 647 & 20 & 627 & Probable & $\star \star \star \star \star \star \star ~$ \\
\hline Chen W-Q, $2009^{68}$ & China & SARS & Retrospective cohort & 758 & 91 & 667 & Confirmed & 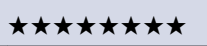 \\
\hline Ho KY, $2004^{83}$ & Singapore & SARS & Prospective cohort & 303 & 8 & 295 & Confirmed & 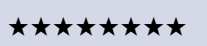 \\
\hline Lau, $2004^{69}$ & Hong Kong & SARS & Case control & 215 & 72 & 143 & Confirmed & 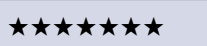 \\
\hline Liu, $2009^{70}$ & China & SARS & Case control & 477 & 51 & 426 & Probable & 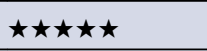 \\
\hline Loeb, $2004^{71}$ & Canada & SARS & Retrospective cohort & 43 & 8 & 35 & Probable & $\star \star$ \\
\hline Nishiura, $2005^{72}$ & Vietnam & SARS & Case control & 115 & 25 & 90 & Confirmed & $\star \star \star \star \star \star \star \star \star \star ~$ \\
\hline Nishiyama, $2008^{73}$ & Vietnam & SARS & Prospective cohort & 146 & 59 & 87 & Confirmed & 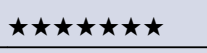 \\
\hline Pei, $2006^{67}$ & China & SARS & Case control & 443 & 147 & 296 & Confirmed & 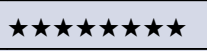 \\
\hline Raboud, $2010^{74}$ & Canada & SARS & Retrospective Cohort & 624 & 26 & 598 & Confirmed & 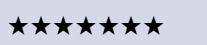 \\
\hline Reynolds, $2006^{75}$ & Vietnam & SARS & Case control & 193 & 36 & 157 & Confirmed & $\star \star \star$ \\
\hline Teleman, $2004^{63}$ & Singapore & SARS & Case control & 86 & 36 & 50 & Confirmed & 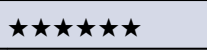 \\
\hline Wang F-D, $2007^{64}$ & Taiwan & SARS & Retrospective cohort & 2,197 & 9 & 2,188 & Confirmed & $\star \star \star \star \star$ \\
\hline Wilder-Smith, $2005^{65}$ & Singapore & SARS & Retrospective cohort & 80 & 45 & 35 & Confirmed & 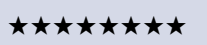 \\
\hline
\end{tabular}

Note. SARS, severe acute respiratory syndrome; MERS, Middle East respiratory syndrome coronavirus; WHO, World Health Organization. Higher number of stars indicates lower risk of bias. WHO case definition in Appendix 6 (online).

not clearly define the setting in which this occurred. ${ }^{27,35}$ Furthermore, most studies of N95 respirators did not provide detail on the comparison group (eg, surgical mask, no mask) and had varying definitions for the use of N95 respirators, such as use all of the time, ${ }^{40}$ always while in an infected patient's room, ${ }^{74,85}$ or during intubation. ${ }^{61}$

Across 13 studies, ${ }^{36,40,49-51,55,60,63,65,68,69,72,74}$ compared to controls (no hand hygiene), hand hygiene following exposure to patients showed an overall significant protective effect $(\mathrm{OR}$, 0.54; 95\% CI, 0.34-0.87; $P=.012$ ) (low certainty; Table 2; Appendix 4, Fig. 7 online). IPAC training (6 studies ${ }^{40,67-70,74}$ ) was associated with a large reduction in infection risk $(\mathrm{OR}, 0.24$; $95 \mathrm{CI} \%, 0.14-0.42 ; P<.001)$ with an overall risk reduction of 17.1\% (95\% CI, 12.4\%-20.1\%; moderate certainty; Table 2; Appendix 4, Fig. 8 online). Compared to no H1N1 vaccine, $\mathrm{H} 1 \mathrm{~N} 1$ vaccine was strongly protective during the $\mathrm{H} 1 \mathrm{~N} 1$ pandemic (OR, 0.10; 95\% CI, 0.04-0.22; $P<.001$ ) (moderate certainty; Appendix 4, Fig. 9 online). ${ }^{51,57,60}$

Compared to control (no involvement in intubation procedures), involvement in intubation (8 studies $\mathrm{s}^{32,38,63,67,68,70,71,74}$ ) was associated with a significant increase in infection risk (OR, 4.72; 95\% CI, $2.71-8.24 ; P<.001)(57.3 \%$ in intubation vs $22.1 \%$ in no intubation; moderate certainty) (Table 2; Appendix 4, Fig. 10 online). Across 19 studies, ${ }^{32,36,38,51,60,63,67-71,74}$ a composite measure of AGMPs was associated with significant increased risk of infection (OR, 2.42; 95\% CI, $1.53-3.82$; $P<.001$ ) (41.5\% in AGMPs vs $22.7 \%$ in no AGMPs; moderate certainty; Fig. 3; Table 2). On subgroup analysis, significantly increased odds of infection were only seen with SARS (OR, 2.95; 95\% CI, 1.68-5.18; $P<.001)$ and not for COVID-19 or H1N1 (Fig. 3). Meta-regression analysis, including covariates of designated status (designated center vs unidentified center), IPAC measures (implemented vs unimplemented or undefined), AGMP type (intubation vs other AGMPs), ICU versus non-ICU, and virus type was performed $\left(\tau^{2}=0.2428 ; \mathrm{I}^{2}=73 \% ; \mathrm{R}^{2}=0.61\right)$ (Appendix 5, Table 2 online). The rate of infection associated with performing AGMPs was a significantly lower in designated facilities compared than in those not identified as such (OR, -1.30 ; 95\% CI, -2.52 to -0.08 ; $P=.037)$. A higher rate of infection was associated with intubation compared to other AGMPs (OR, 1.04; 95\% CI, 0.30-1.77; $P=.006$ ) (Appendix 5, Fig. 3 online).

Summary odds ratios for meta-analyzed risk factors are reported in Figure 4. To emphasize the meta-analysed effect estimates of risk factors with greater robustness, additional metaanalysis with $99 \%$ confidence intervals were conducted. In this analysis, risk factors with effect estimates that persisted toward significant effect included frontline HCW, gloves, surgical masks, N95 masks, face protection, IPAC training, H1N vaccination, intubation, and participation in AGMPs (Appendix 6 online).

\section{Discussion}

This systematic review and meta-regression analysis provides a comprehensive summary of occupational risk factors for HCW infection during viral respiratory pandemics. Our findings suggest that compared to nonfrontline HCWs, frontline HCWs are at significantly increased risk of infection during an outbreak (low certainty). Use of gloves, gowns, surgical masks, N95 respirators, and face protection, as well as receiving IPAC training were each associated with large reductions in infection (moderate certainty). Compared to other AGMPs, endotracheal intubation of patients with coronaviruses SARS-CoV-1 and SARS-CoV-2 was associated with a very large increase in the HCW infection rate (moderate certainty). Meta-regression analysis revealed that the availability of isolation wards was protective from infection among frontline HCWs and those performing AGMPs.

The safety of HCWs is paramount for many reasons, including the facilitation of continuous patient care, prevention of virus infection for themselves and also spread to other patients, as well as an ethical duty to protect those who put themselves on the frontline to treat others. The results of our review demonstrate the efficacy of well-known measures, such as PPE adherence and IPAC training, against viral respiratory pathogens that have stood as pillars of infection prevention and control in healthcare settings. The delivery of adequate IPAC training also poses its own barriers, including constantly changing guidelines, poor communication 
Table 2. Grading of Recommendations, Assessment, Development, and Evaluation (GRADE) of Meta-Analyzed Outcomes by 3 Knowledge Questions

\begin{tabular}{|c|c|c|c|c|c|c|c|c|c|c|}
\hline \multicolumn{7}{|c|}{ Certainty Assessment } & \multicolumn{4}{|c|}{ Summary of Findings } \\
\hline \multirow[b]{2}{*}{$\begin{array}{l}\text { No. of Studies } \\
\text { (Total } \\
\text { Participants) }\end{array}$} & \multirow[b]{2}{*}{ Risk of Bias } & \multirow[b]{2}{*}{ Inconsistency } & \multirow[b]{2}{*}{ Indirectness } & \multirow[b]{2}{*}{ Imprecision } & \multirow[b]{2}{*}{ Other Considerations ${ }^{\dagger}$} & \multirow[b]{2}{*}{$\begin{array}{l}\text { Overall Certainty of } \\
\text { Evidence }\end{array}$} & \multicolumn{2}{|c|}{$\begin{array}{l}\text { Anticipated Absolute Risk } \\
\text { (ie, Chance of Viral } \\
\text { Infection) }\end{array}$} & \multirow[b]{2}{*}{$\begin{array}{c}\text { Risk } \\
\text { Difference, \% } \\
(95 \% \mathrm{Cl}) \\
\end{array}$} & \multirow[b]{2}{*}{ Anticipated Effects } \\
\hline & & & & & & & $\begin{array}{l}\text { Control } \\
\text { Risk, \% } \\
(95 \% \mathrm{Cl})\end{array}$ & $\begin{array}{l}\text { Intervention } \\
\text { Risk, \% (95\% } \\
\text { CI) }\end{array}$ & & \\
\hline \multicolumn{11}{|c|}{ A) Knowledge Question \#1: Which types of HCW are at increased risk of infection? } \\
\hline \multicolumn{11}{|c|}{ Frontline vs. non-frontline HCW } \\
\hline $32(31,308)$ & Not serious ${ }^{\mathrm{a}}$ & Not serious ${ }^{b}$ & Not serious ${ }^{\mathrm{e}}$ & Not serious & None & $\oplus \oplus$ & 7.6 & $\begin{array}{c}12.0 \\
(9.3-15.4)\end{array}$ & $\begin{array}{c}4.4 \\
(1.7-7.8)\end{array}$ & $\begin{array}{l}\text { Frontline HCW may be at } \\
\text { considerable increased risk of } \\
\text { infection compared to } \\
\text { non-frontline HCW. }\end{array}$ \\
\hline \multicolumn{11}{|c|}{ Physicians (reference group) vs. nurses } \\
\hline $29(131,794)$ & Not serious ${ }^{\mathrm{a}}$ & Not serious ${ }^{b}$ & Not serious ${ }^{e}$ & Not serious & None & $\oplus \oplus$ & 3.1 & $\begin{array}{c}2.9 \\
(2.4-3.5)\end{array}$ & $\begin{array}{c}-0.2 \\
(-0.7 \text { to } 0.4)\end{array}$ & $\begin{array}{l}\text { There may be little to no } \\
\text { difference in rate of infection } \\
\text { between physicians and nurses. }\end{array}$ \\
\hline \multicolumn{11}{|c|}{ B) Knowledge Question \#2: Which infection prevention and control practice are associated with protective effects for infection in HCW? } \\
\hline \multicolumn{11}{|l|}{ Gloves } \\
\hline $16(4,498)$ & Not serious ${ }^{\mathrm{a}}$ & Not serious ${ }^{b}$ & Not seriouse & Not serious & Strong associationg & MODERATE & 25.7 & $\begin{array}{c}14.3 \\
(9.7-20.6)\end{array}$ & $\begin{array}{c}-11.5 \\
(-16.0 \text { to }-5.1)\end{array}$ & $\begin{array}{l}\text { The use of gloves probably } \\
\text { results in a large reduction of } \\
\text { infection risk. }\end{array}$ \\
\hline \multicolumn{11}{|l|}{ Gown } \\
\hline $8(3,048)$ & Not serious ${ }^{\mathrm{a}}$ & Not serious ${ }^{b}$ & Not serious ${ }^{\mathrm{e}}$ & Not serious & Strong associationg & MODERATE & 30.6 & $\begin{array}{c}16.9 \\
(9.9-16.0) \\
\end{array}$ & $\begin{array}{c}-13.7 \\
(-20.7 \text { to }-3.3) \\
\end{array}$ & $\begin{array}{l}\text { Gown use probably result in a } \\
\text { large reduction of infection risk. }\end{array}$ \\
\hline \multicolumn{11}{|l|}{ Surgical mask } \\
\hline $12(1,960)$ & Not serious ${ }^{\mathrm{a}}$ & Not serious ${ }^{b c}$ & Not serious ${ }^{e}$ & Not serious & Strong associationg & MODERATE & 20.6 & $\begin{array}{c}8.8 \\
(4.9-14.6)\end{array}$ & $\begin{array}{c}-11.9 \\
(-15.7 \text { to }-6.0)\end{array}$ & $\begin{array}{l}\text { Surgical mask use probably } \\
\text { results in a large reduction in } \\
\text { infection risk. }\end{array}$ \\
\hline \multicolumn{11}{|l|}{ N95 mask } \\
\hline $15(9,178)$ & Not serious ${ }^{\mathrm{a}}$ & Not serious ${ }^{b}$ & Not serious ${ }^{\mathrm{e}}$ & Not serious & $\begin{array}{l}\text { Strong associationg; } \\
\text { publication bias }^{\mathrm{h}}\end{array}$ & MODERATE & 6.6 & $\begin{array}{c}2.2 \\
(1.3-3.5) \\
\end{array}$ & $\begin{array}{c}-4.4 \\
(-5.2 \text { to }-3.0)\end{array}$ & $\begin{array}{l}\text { N95 use probably results in a } \\
\text { large reduction of infection. }\end{array}$ \\
\hline \multicolumn{11}{|c|}{ Face protection } \\
\hline $11(5,116)$ & Not serious ${ }^{\mathrm{a}}$ & Not serious ${ }^{b}$ & Not serious ${ }^{\mathrm{e}}$ & Not serious & $\begin{array}{l}\text { Strong associationg; } \\
\text { publication bias }\end{array}$ & MODERATE & 19.9 & $\begin{array}{c}9.2 \\
(6.3-13.3)\end{array}$ & $\begin{array}{c}-10.6 \\
(-13.6 \text { to }-6.5)\end{array}$ & $\begin{array}{l}\text { Wearing goggles or face shields } \\
\text { probably results in a large } \\
\text { reduction of infection. }\end{array}$ \\
\hline \multicolumn{11}{|l|}{ Hand hygiene } \\
\hline $13(3,499)$ & Not serious ${ }^{\mathrm{a}}$ & Not serious ${ }^{d}$ & Not serious ${ }^{\mathrm{e}}$ & Not serious & Publication bias ${ }^{h}$ & $\oplus \oplus$ & 14.6 & $\begin{array}{c}8.5 \\
(5.5-13.0)\end{array}$ & $\begin{array}{c}-6.1 \\
(-9.1 \text { to }-1.6)\end{array}$ & $\begin{array}{l}\text { Hand hygiene may result in } \\
\text { considerable reduction in } \\
\text { infection risk. }\end{array}$ \\
\hline
\end{tabular}




\begin{tabular}{|c|c|c|c|c|c|c|c|c|c|c|}
\hline \multicolumn{11}{|c|}{ Infection control and prevention training } \\
\hline $6(2,589)$ & Not serious ${ }^{\mathrm{a}}$ & Not serious ${ }^{b}$ & Not serious ${ }^{e}$ & Not serious & Strong associationg & MODERATE & 24.4 & $\begin{array}{c}7.2 \\
(4.3-12.0)\end{array}$ & $\begin{array}{l}-17.1 \\
(-20.1 \text { to } \\
-12.4)\end{array}$ & $\begin{array}{l}\text { Infection control training } \\
\text { probably results in a large } \\
\text { reduction in infection risk. }\end{array}$ \\
\hline \multicolumn{11}{|c|}{ H1N1 vaccine (during H1N1 pandemic) ${ }^{i}$} \\
\hline $3(1,527)$ & Not serious ${ }^{\mathrm{a}}$ & Not serious ${ }^{\mathrm{c}}$ & Not serious ${ }^{\mathrm{e}}$ & Not serious & Strong associationg & MODERATE & 3.6 & $\begin{array}{c}0.4 \\
(0.2-0.8)\end{array}$ & $\begin{array}{c}-3.2 \\
(-3.5 \text { to }-2.8)\end{array}$ & $\begin{array}{l}\text { Receiving H1N1 vaccine } \\
\text { probably reduces rate of H1N1 } \\
\text { infection during an outbreak. }\end{array}$ \\
\hline \multicolumn{11}{|c|}{ C) Knowledge Question \#3: What is the association of AGMPs with infection in HCW? } \\
\hline \multicolumn{11}{|c|}{ Participation in intubation procedure } \\
\hline $8(3,208)$ & Not serious ${ }^{\mathrm{a}}$ & Not serious ${ }^{b}$ & Not serious ${ }^{\mathrm{e}}$ & Not serious & Strong associationg & MODERATE & 22.1 & $\begin{array}{c}57.3 \\
(43.5-70.1)\end{array}$ & $\begin{array}{c}35.2 \\
(21.4-47.9)\end{array}$ & $\begin{array}{l}\text { Involvement in intubation } \\
\text { procedures probably causes } \\
\text { large increases in risk of } \\
\text { infection. }\end{array}$ \\
\hline \multicolumn{11}{|c|}{ Participation in aerosol generating medical procedures, including intubation } \\
\hline $19(6,897)$ & Not serious ${ }^{\mathrm{a}}$ & Not serious ${ }^{b}$ & Not serious ${ }^{\mathrm{e}}$ & Not serious & Strong associationg & MODERATE & 22.7 & $\begin{array}{c}41.5 \\
(31.0-52.9)\end{array}$ & $\begin{array}{c}18.8 \\
(8.3-30.2)\end{array}$ & $\begin{array}{l}\text { Performance of aerosol } \\
\text { generating medical procedures } \\
\text { probably results in a } \\
\text { considerable increase in rate of } \\
\text { infection. }\end{array}$ \\
\hline
\end{tabular}

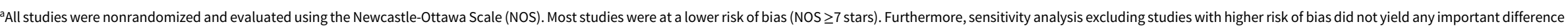

in effect. Therefore, risk of bias was not downgraded.
${ }^{b}$ While there was a high $I^{2}$ value, there was a large amount of overlapping of confidence intervals and low variation of effect estimates across studies. Thus, inconsistency was not downgraded.

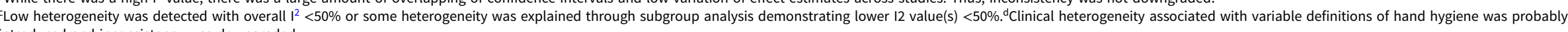
introduced and inconsistency was downgraded.

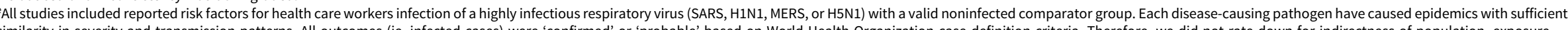

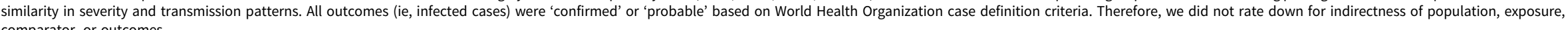
comparator, or outcomes.

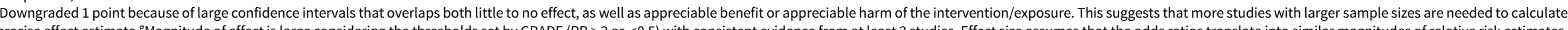

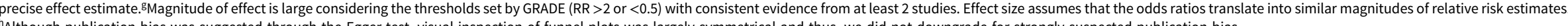

Although publication bias was suggested through the Egger test, visua in 


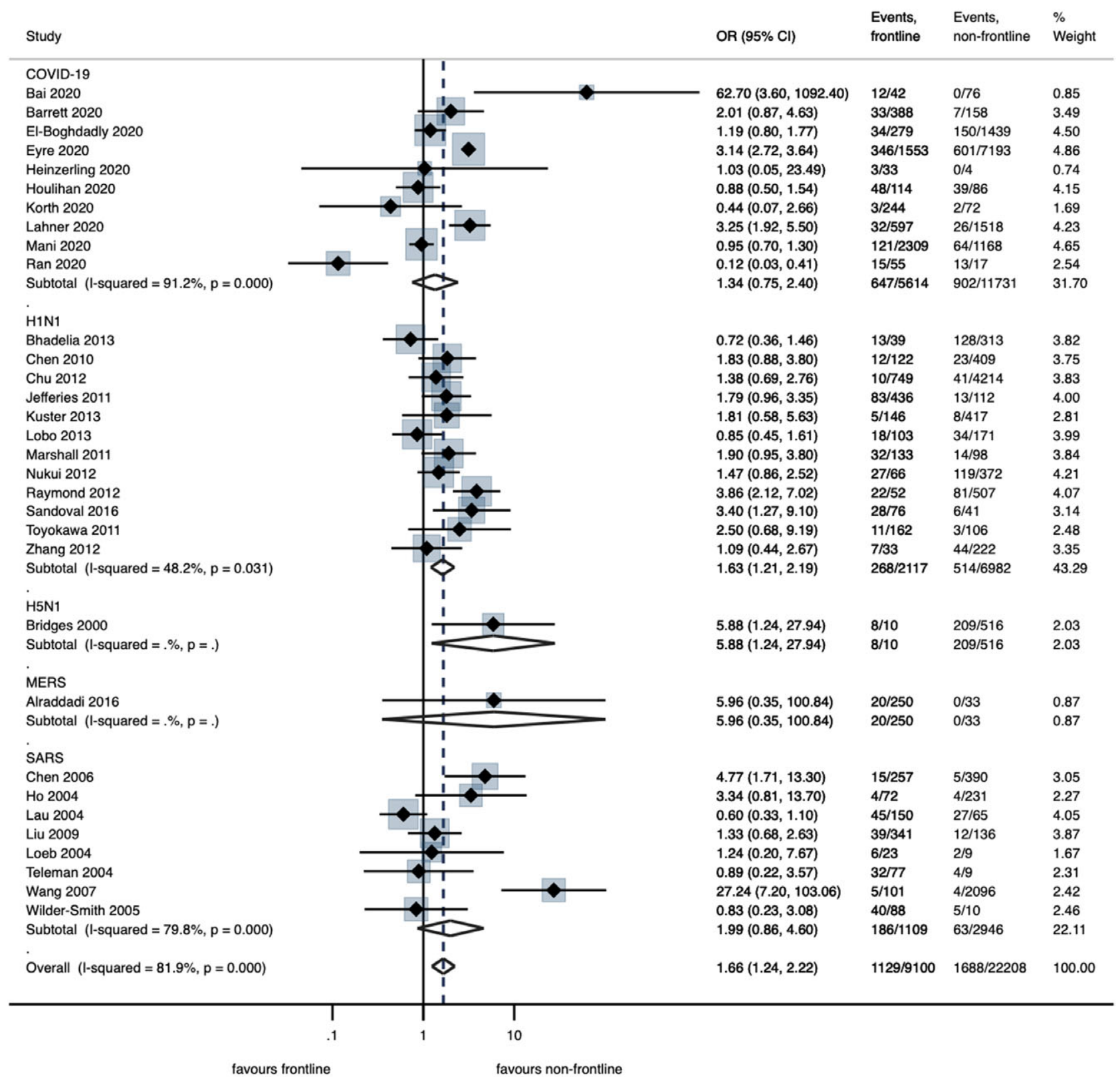

Fig. 2. Forest plot of random effect meta-analysis of the risk of infection in frontline healthcare workers (HCWs) by virus type. Frontline HCWs were defined as those with high occurrence of patient face-to-face contact, including emergency department staff, intensive care unit staff, and HCWs who responded affirmatively to having direct exposure with patients.

and enforcement of guidelines, and increased workload and fatigue in HCWs, which may be heightened during a pandemic lasting many months. ${ }^{86}$ Thus, despite the novelty of SARS-CoV-2, it is likely that interventions long-practiced in acute-care sites across the globe are adequate to protect frontline staff against the virus. ${ }^{87}$

Our findings regarding the protective effects of PPE use and increased transmission risk associated with AGMPs are generally consistent with results from previous reviews in the HCW population. ${ }^{13,88-91}$ A recent rapid review reported that in healthcare settings, risk for infection with SARS-CoV-1 was likely decreased with mask use versus no mask use and possibly decreased with N95 versus surgical mask use, with uncertain applicability to SARS-CoV-2 due to lack of direct evidence, This finding is generally consistent with our report relating to mask effectiveness and SARS-CoV-2. ${ }^{92}$
Of the 3 studies reporting a significant increase in risk for involvement in AGMPs, these procedures included endotracheal intubation and nebulization therapy with inconsistent reports of PPE use during the procedure. ${ }^{60,68,70}$ Critically, none of these 3 studies addressed whether proper PPE was worn by personnel during these procedures, including use of N95 respirators. Based on these and other findings, national guidelines therefore universally recommend N95 respirators during AGMPs performed on patients with COVID-19.93-96

The strengths of this study are that it identified a multitude of different factors relating to infection risk during previous respiratory viral epidemics representative worldwide through stringent methodology of data synthesis. Nearly all included studies met the WHO criteria for confirmed positive cases for each respective disease, 


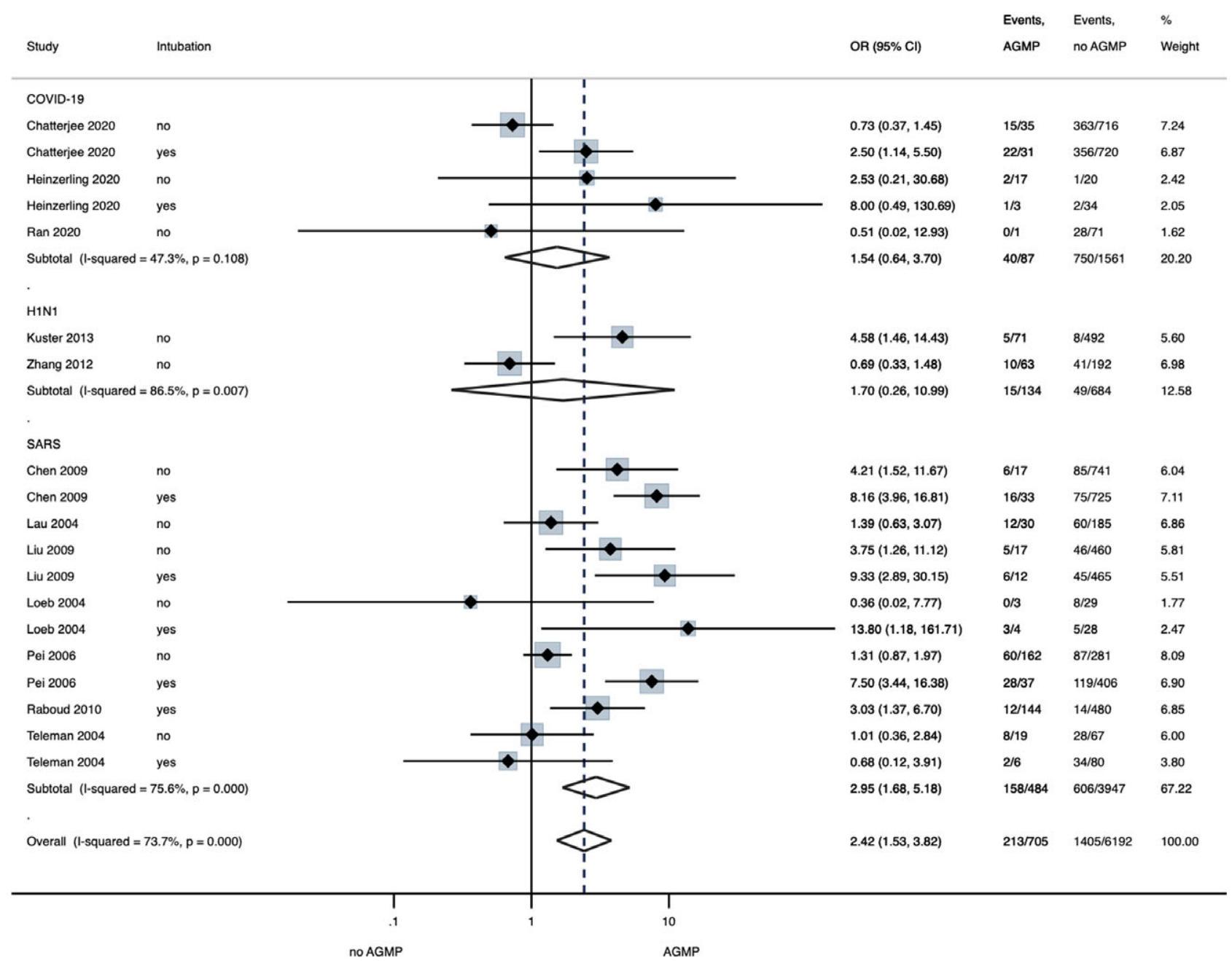

Fig. 3. Forest plot of random effect meta-analysis of the association of aerosol-generating medical procedures (AGMPs) on infection in HCWs by virus type. AGMPs include endotracheal intubation, chest compressions, and other airway manipulations.

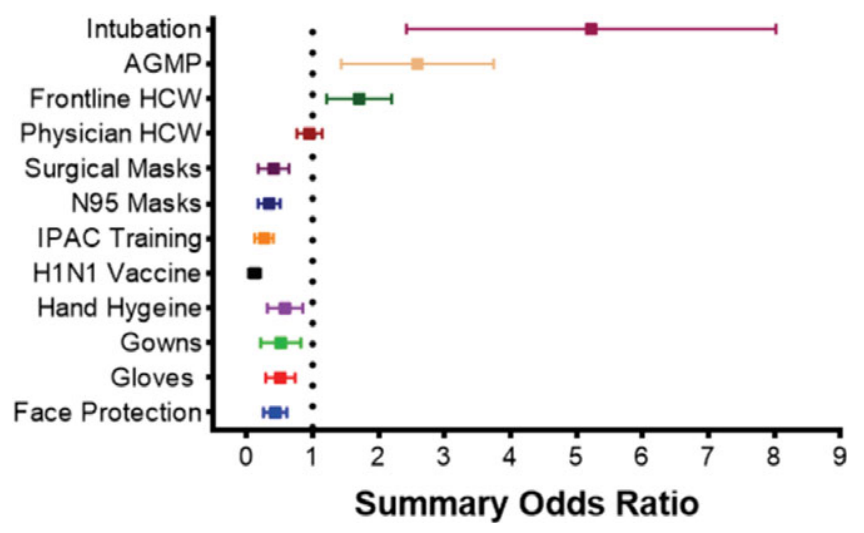

Fig. 4. Forest plot of all the summary odds ratios for meta-analysed risk factors. *Represents the overall odds ratios for meta-analysed risk factors on healthcare worker infection during all included viral respiratory pandemics. Comparator groups: intubation versus no intubation; AGMP versus no AGMP; frontline $\mathrm{HCW}$ versus non-frontline $\mathrm{HCW}$; physician versus nurse; surgical mask versus no surgical mask; N95 mask versus no N95 mask; IPAC training versus no IPAC training; hand hygiene versus no hand hygiene; gowns versus no gowns; gloves versus no gloves; face protection versus no face protection. ensuring the accuracy of cases and controls (Appendix 7 online). Our review highlights respiratory viruses with transmission profiles and reproductive numbers comparable to SARS-CoV-2, thereby increasing the generalizability of our findings and their applicability to the ongoing pandemic, distinct from previous reviews. ${ }^{90,97,98}$ Finally, we used the GRADE approach to facilitate transparent recommendations and interpretations of the data. ${ }^{25}$

Although stringent methods were adhered to, limitations were inherent in the current review. First, randomized trials were lacking due to the inherent ethical risk of restricting protective measures during an emerging epidemic. Most studies were of retrospectively design, potentially leading to selection and measurement biases and failure to match for potential confounding variables such as age, sex, and baseline comorbidities. ${ }^{91} \mathrm{We}$ also observed also heterogeneity introduced in the meta-analysis of many unique viral pathogens, each with different epidemiological profiles. Furthermore, the differences in global impact of the various pathogens $(8,098$ worldwide SARS-CoV-1 cases versus 56 million worldwide SARS-CoV-2 cases and increasing) introduced heterogeneity in meta-analyzed risk factors, potentially reducing the certainty of evidence for certain findings. ${ }^{99,100}$ We conducted 
a pathogen-specific stratified meta-analysis to address these differences. However, few individual patient factors were reported (eg, ethnicity, sociodemographic factors, and comorbidity status) that likely influence $\mathrm{HCW}$ susceptibility to infection. ${ }^{101}$ Emerging literature suggests that black, Asian, and minority ethnic individuals are at increased risk of SARS-CoV-2 infection, with worse clinical outcomes. ${ }^{102}$ Heterogeneity was observed in classifying the various risk factors. Few studies have explored the role of HCW-to-HCW transmission of pathogens, which has been associated with an increased risk of SARS-CoV-2 transmission in HCW without adherence to medical mask use in break rooms and during meals. ${ }^{9}$ Moreover, data on compliance with hand hygiene or proper donning and doffing technique and staff surveillance strategies were limited, and both of these factors have been shown to be critical in reducing the infection risk. ${ }^{90,103,104}$ These limitations were addressed by conducting meta-regression, controlling for virus type, and various covariates, and thereby adjusted estimates provide a conservative assessment of the risk to HCWs. The protective effects of each individual PPE item may be confounded by the reality that PPE is usually worn in bundles (eg, mask with face shield, gloves, and gown) and therefore may not reflect the true effect estimates of each PPE item, and these protective effects may be additive in when adhering to PPE bundles. Lastly, restriction of articles to the English language, to produce a timely review, may have excluded potentially relevant studies.

Amid the evolving COVID-19 pandemic, rapidly released research has attempted to answer many questions regarding the safety of HCWs caring for patients with COVID-19. Our review has shown that some key questions remain to be answered, including efforts to report detailed data for ethnicity, sociodemographic factors and comorbidity status, and direct head-to-head comparison of N95 respirators and surgical masks in the routine care of patients with COVID-19, a topic which has yet to be directly addressed by current evidence. ${ }^{98,101,105}$

In conclusion, this systematic review and meta-analysis synthesizes the current evidence for the risk of infection among HCWs in a viral respiratory outbreak and draws attention to useful protective strategies while caring for patients, especially for frontline HCWs performing risk-prone exposures. IPAC measures should be instituted, preferably in dedicated settings, to protect frontline HCWs during current and future waves of respiratory virus pandemics.

\section{Acknowledgments.}

Financial support. Support was provided solely from institutional and/or departmental sources. MS is supported by the Canadian Anesthesiologists Society Career Scientist Award, as well as the Merit Awards Program from the Department of Anesthesia at the University of Toronto.

Conflict of interests. M.S. serves on the medical advisory board of the Hypersomnia Foundation on a voluntary basis. The remaining authors declare no competing interests.

Supplementary material. To view supplementary material for this article, please visit https://doi.org/10.1017/ice.2021.18

\section{References}

1. Chan JF-W, Yuan S, Kok K-H, et al. A familial cluster of pneumonia associated with the 2019 novel coronavirus indicating person-to-person transmission: a study of a family cluster. Lancet 2020;395:514-523.

2. Mondelli MU, Colaneri M, Seminari EM, Baldanti F, Bruno R. Low risk of SARS-CoV-2 transmission by fomites in real-life conditions. Lancet Infect Dis 2020. doi: 10.1016/S1473-3099(20)30678-2.
3. Sepkowitz KA, Eisenberg L. Occupational deaths among healthcare workers. Emerg Infect Dis 2005;11:1003-1008.

4. Booth CM, Matukas LM, Tomlinson GA, et al. Clinical features and shortterm outcomes of 144 patients with SARS in the greater Toronto area. JAMA 2003;289:2801-2809.

5. Lee $\mathrm{N}$, Hui $\mathrm{D}, \mathrm{Wu} \mathrm{A}$, et al. A major outbreak of severe acute respiratory syndrome in Hong Kong. N Engl J Med 2003;348:1986-1994.

6. Guzzetta G, Marziano V, Poletti P, et al. Epidemia COVID-19: Aggiornamento Nazionale 14 Luglio 2020 - Ore 11:00. Epicentro website. https://www. epicentro.iss.it/coronavirus/bollettino/Bollettino-sorveglianza-integrataCOVID-19_14-luglio-2020.pdf. Published 2020. Accessed January 2021.

7. Suwantarat N, Apisarnthanarak A. Risks to healthcare workers with emerging diseases: lessons from MERS-CoV, Ebola, SARS, and avian flu. Curr Opin Infect Dis 2015;28:349-361.

8. Chan-Yeung M. Severe acute respiratory syndrome (SARS) and healthcare workers. Int J Occup Environ Health 2004;10:421-427.

9. Çelebi G, Pişkin N, Çelik Bekleviç A, et al. Specific risk factors for SARSCoV-2 transmission among health care workers in a university hospital. Am J Infect Control 2020;48:1225-1230.

10. Wang W, Brull R, Patel N, Massouh F, Abdallah FW. Risk of respiratory complications in obese patients in obese patients receiving interscalene nerve block: a multicenter retrospective matched cohort study. Shields Day presentation, University of Toronto, Toronto, Canada.

11. Chirico F, Nucera G, Magnavita N. COVID-19: protecting healthcare workers is a priority. Infect Control Hosp Epidemiol 2020;41:1117.

12. Islam MS, Rahman KM, Sun Y, et al. Current knowledge of COVID-19 and infection prevention and control strategies in healthcare settings: a global analysis. Infect Control Hosp Epidemiol 2020;41:1196-1206.

13. Chu DK, Akl EA, Duda S, et al. Physical distancing, face masks, and eye protection to prevent person-to-person transmission of SARS-CoV-2 and COVID-19: a systematic review and meta-analysis. Lancet 2020;6736(20):1-15.

14. Kisely S, Warren N, McMahon L, Dalais C, Henry I, Siskind D. Occurrence, prevention, and management of the psychological effects of emerging virus outbreaks on healthcare workers: rapid review and meta-analysis. BMJ 2020;369:m1642.

15. Liberati A, Altman DG, Tetzlaff J, et al. The PRISMA statement for reporting systematic reviews and meta-analyses of studies that evaluate healthcare interventions: explanation and elaboration. BMJ 2009;339:b2700.

16. Stroup DF, Berlin JA, Morton SC, et al. Meta-analysis of observational studies in epidemiology: a proposal for reporting. Meta-analysis Of Observational Studies in Epidemiology (MOOSE) group. JAMA 2000;283:2008-2012.

17. Garritty C, Gartlehner G, Kamel C, et al. Cochrane Rapid Reviews. Interim guidance from the Cochrane Rapid Reviews Methods Group. March 2020.

18. Protocol for assessment of potential risk factors for 2019-novel coronavirus (2019-nCoV) infection among health care workers in a health care setting. World Health Organization (WHO) website. https:/www.who.int/ publications-detail/protocol-for-assessment-of-potential-risk-factors-for-2019novel-coronavirus-(2019-ncov)-infection-among-health-care-workers-ina-health-care-setting. Published February 2020. Accessed January 2021.

19. Verbeek JH, Rajamaki B, Ijaz S, et al. Personal protective equipment for preventing highly infectious diseases due to exposure to contaminated body fluids in healthcare staff. Cochrane Database Syst Rev 2019;7(7): CD011621.

20. StataCorp. 2017. Stata Statistical Software: Release 15. College Station, TX: StataCorp LLC.

21. Borenstein M, Hedges L, Higgins J, Rothstein H. Comprehensive Metaanalysis Version 3. Englewood, NJ: Biostat; 2013.

22. Stang A. Critical evaluation of the Newcastle-Ottawa scale for the assessment of the quality of nonrandomized studies in meta-analyses. Eur J Epidemiol 2010;25:603-605.

23. Peterson J, Welch V, Losos M, Tugwell P. The Newcastle-Ottawa scale (NOS) for assessing the quality of nonrandomised studies in meta-analyses. Ottawa Hospital Research Institute website. http://www.ohri.ca/ programs/clinical_epidemiology/oxford.asp. Published 2011. Accessed Janaury 2021. 
24. Moskalewicz A, Oremus M. No clear choice between Newcastle-Ottawa scale and appraisal tool for cross-sectional studies to assess methodological quality in cross-sectional studies of health-related quality of life and breast cancer. J Clin Epidemiol 2020;120:94-103.

25. Guyatt G, Oxman AD, Akl EA, et al. GRADE guidelines: 1. IntroductionGRADE evidence profiles and summary of findings tables. J Clin Epidemiol 2011;64:383-394.

26. Zheng L, Wang X, Zhou C, et al. Analysis of the infection status of the health care workers in Wuhan during the COVID-19 outbreak: a cross-sectional study. Clin Infect Dis 2020;71:2109-2113.

27. Wang X, Pan Z, Cheng Z. Association between 2019-nCoV transmission and N95 respirator use. J Hosp Infect 2020;105:104-105.

28. Lahner E, Dilaghi E, Prestigiacomo C, et al. Prevalence of SARS-CoV-2 infection in health workers (HWs) and diagnostic test performance: the experience of a teaching hospital in central Italy. Int J Environ Res Public Health 2020;17:4417.

29. Korth J, Wilde B, Dolff S, et al. SARS-CoV-2-specific antibody detection in healthcare workers in Germany with direct contact to COVID-19 patients. J Clin Virol 2020;128:104437.

30. Chen Y, Tong X, Wang J, et al. High SARS-CoV-2 antibody prevalence among healthcare workers exposed to COVID-19 patients. J Infect 2020. doi: 10.1016/j.jinf.2020.05.067.

31. Barrett ES, Horton DB, Roy J, et al. Prevalence of SARS-CoV-2 infection in previously undiagnosed health care workers at the onset of the US COVID-19 epidemic. medRxiv Prepr Serv Heal Sci April 24, 2020. doi: 10.1101/2020.04.20.20072470.

32. Chatterjee P, Anand T, Singh KJ, et al. Healthcare workers \& SARS-CoV-2 infection in India: a case-control investigation in the time of COVID-19. Indian J Med Res 2020;151:459-467.

33. Eyre DW, Lumley SF, Donnell D, et al. Differential occupational risks to healthcare workers from SARS-CoV-2: a prospective observational study. medRxiv January 1, 2020. doi: 10.1101/2020.06.24.20135038.

34. Houlihan C, Vora N, Byrne T, et al. SARS-CoV-2 virus and antibodies in front-line healthcare workers in an acute hospital in London: preliminary results from a longitudinal study. medRxiv January 1, 2020. doi: 10.1101/ 2020.06.08.20120584.

35. Wang Q, Huang X, Bai Y, et al. Epidemiological characteristics of COVID-19 in medical staff members of neurosurgery departments in Hubei province: a multicentre descriptive study. medRxiv April 20, 2020. doi: 10.1101/2020.04.20.20064899.

36. Ran L, Chen X, Wang Y, Wu W, Zhang L, Tan X. Risk factors of healthcare workers with coronavirus disease 2019: a retrospective cohort study in a designated hospital of Wuhan in China. Clin Infect Dis 2020;71:22182221.

37. Lai X, Wang M, Qin C, et al. Coronavirus disease 2019 (COVID-2019) infection among healthcare workers and implications for prevention measures in a tertiary hospital in Wuhan, China. JAMA Netw Open 2020;3(5): e209666.

38. Heinzerling A, Stuckey MJ, Scheuer T, et al. Transmission of COVID-19 to healthcare personnel during exposures to a hospitalized patientSolano County, California, February 2020. Morb Mortal Wkly Rep 2020;69:472-476.

39. El-Boghdadly K, Wong DJN, Owen R, et al. Risks to healthcare workers following tracheal intubation of patients with COVID-19: a prospective international multicentre cohort study. Anaesthesia 2020;75:1437-1447.

40. Guo X, Wang J, Hu D, et al. Survey of COVID-19 disease among orthopaedic surgeons in Wuhan, People's Republic of China. J Bone Jt Surg Am 2020;102:847-854.

41. Bai Y, Wang X, Huang Q, et al. SARS-CoV-2 infection in health care workers: a retrospective analysis and a model study. medRxiv March 29, 2020. doi: 10.1101/2020.03.29.20047159

42. Mani NS, Budak JZ, Lan KF, et al. Prevalence of COVID-19 infection and outcomes among symptomatic healthcare workers in Seattle, Washington. Clin Infect Dis 2020;71:2702-2707.

43. Balkhy HH, El-Saed A, Sallah M. Epidemiology of H1N1 (2009) influenza among healthcare workers in a tertiary care center in Saudi Arabia: a 6-month surveillance study. Infect Control Hosp Epidemiol 2010;31: 1004-1010.
44. Bandaranayake D, Huang QS, Bissielo A, et al. Risk factors and immunity in a nationally representative population following the 2009 influenza A(H1N1) pandemic. PLoS One 2010;5(10):e13211.

45. Lobo RD, Oliveira MS, Garcia CP, Caiaffa Filho HH, Levin AS. Pandemic 2009 H1N1 influenza among healthcare workers. Am J Infect Control 2013;41:645-647.

46. Marshall C, Kelso A, McBryde E, et al. Pandemic (H1N1) 2009 risk for frontline health care workers. Emerg Infect Dis 2011;17:1000-1006.

47. Nukui $Y$, Hatakeyama S, Kitazawa T, Mahira T, Shintani Y, Moriya K. Pandemic 2009 influenza A (H1N1) virus among Japanese healthcare workers: seroprevalence and risk factors. Infect Control Hosp Epidemiol 2012;33:58-62.

48. Raymond NJ, Berry N, Blackmore TK, et al. Pandemic influenza A (H1N1) 2009 in hospital healthcare workers in New Zealand. Infect Control Hosp Epidemiol 2012;33:196-199.

49. Sandoval C, Barrera A, Ferres M, et al. Infection in health personnel with high and low levels of exposure in a hospital setting during the H1N1 2009 influenza a pandemic. PLoS One 2016;11(1). doi: 10.1371/journal.pone. 0147271.

50. Toyokawa T, Sunagawa T, Yahata Y, et al. Seroprevalence of antibodies to pandemic (H1N1) 2009 influenza virus among health care workers in two general hospitals after first outbreak in Kobe, Japan. J Infect 2011;63: 281-287.

51. Zhang Y, Seale H, Yang P, et al. Factors associated with the transmission of pandemic (H1N1) 2009 among hospital healthcare workers in Beijing, China. Influenza Other Respi Virus 2012;7:466-471.

52. Hudson B, Toop L, Mangin D, Brunton C, Jennings L, Fletcher L. Pandemic influenza A(H1N1)pdm09: risk of infection in primary healthcare workers. Br J Gen Pract 2013;63(611):e416-e422.

53. Bhadelia N, Sonti R, McCarthy JW, et al. Impact of the 2009 influenza A (H1N1) pandemic on healthcare workers at a tertiary care center in New York City. Infect Control Hosp Epidemiol 2013;34:825-831.

54. Chen MIC, Lee VJM, Barr I, et al. Risk factors for pandemic (H1N1) 2009 virus seroconversion among hospital staff, Singapore. Emerg Infect Dis 2010;16:1554-1561.

55. Chokephaibulkit K, Assanasen S, Apisarnthanarak A, et al. Seroprevalence of 2009 H1N1 virus infection and self-reported infection control practices among healthcare professionals following the first outbreak in Bangkok, Thailand. Influenza Other Respir Virus 2013;7:359-363.

56. Chu T-P, Li C-C, Wang L, et al. A surveillance system to reduce transmission of pandemic H1N1 (2009) influenza in a 2,600-bed medical center. PLoS One 2012;7(3):e32731.

57. Costa JT, Silva R, Tavares M, Nienhaus A. High effectiveness of pandemic influenza A (H1N1) vaccination in healthcare workers from a Portuguese hospital. Int Arch Occup Environ Health 2012;85:747-752.

58. Jaeger JL, Patel M, Dharan N, et al. Transmission of 2009 Pandemic Influenza A (H1N1) virus among healthcare personnel—Southern California, 2009. Infect Control Hosp Epidemiol 2011;32:1149-1157.

59. Jefferies S, Earl D, Berry N, et al. Effectiveness of the 2009 seasonal influenza vaccine against pandemic influenza $\mathrm{A}(\mathrm{H} 1 \mathrm{~N} 1) 2009$ in healthcare workers in New Zealand, June-August 2009. Euro Surveill 2011;16(2): pii $=19761$.

60. Kuster SP, Coleman BL, Raboud J, et al. Risk factors for influenza among health care workers during 2009 pandemic, Toronto, Ontario, Canada. Emerg Infect Dis 2013;19:606-615.

61. Caputo KM, Byrick R, Chapman MG, Orser BA, Orser BJ. Intubation of SARS patients: infection and perspectives of healthcare workers. Can J Anesth 2006;53:122-129.

62. Chen YM, Liang SY, Shih YP, et al. Epidemiological and genetic correlates of severe acute respiratory syndrome coronavirus infection in the hospital with the highest nosocomial infection rate in Taiwan in 2003. J Clin Microbiol 2006;44:359-365.

63. Teleman MD, Boudville IC, Heng BH, Zhu D, Leo YS. Factors associated with transmission of severe acute respiratory syndrome among healthcare workers in Singapore. Epidemiol Infect 2004;132:797-803.

64. Wang F-D, Chen Y-Y, Lee Y-M, et al. Positive rate of serum SARS-CoV immunoglobulin $\mathrm{G}$ antibody among healthcare workers. Scand J Infect Dis 2007;39:152-156. 
65. Wilder-Smith A, Teleman MD, Heng BH, Earnest A, Ling AE, Leo YS. Asymptomatic SARS coronavirus infection among healthcare workers, Singapore. Emerg Infect Dis 2005;11:1142-1145.

66. Ho KY, Singh KS, Habib AG, et al. Mild illness associated with severe acute respiratory syndrome coronavirus infection: lessons from a prospective seroepidemiologic study of health-care workers in a teaching hospital in Singapore. J Infect Dis 2004;189:642-647.

67. Pei L, Gao Z, Yang Z, et al. Investigation of the influencing factors on severe acute respiratory syndrome among healthcare workers. Beijing Da Xие Xие Bao 2006;38:271-275.

68. Chen W-Q, Ling W-H, Lu C-Y, et al. Which preventive measures might protect health care workers from SARS? BMC Public Health 2009;9:81.

69. Lau JTF, Fung KS, Wong TW, et al. SARS Transmission among hospital workers in Hong Kong. Emerg Infect Dis 2004;10:280-286.

70. Liu W, Tang F, Fang LQ, et al. Risk factors for SARS infection among hospital healthcare workers in Beijing: a case control study. Trop Med Int Health 2009;14 suppl 1:52-59.

71. Loeb M, McGeer A, Henry B, et al. SARS among critical care nurses, Toronto. Emerg Infect Dis 2004;10:251-255.

72. Nishiura H, Kuratsuji T, Quy T, et al. Rapid awareness and transmission of severe acute respiratory syndrome in Hanoi French Hospital, Vietnam. Am J Trop Med Hyg 2005;73:17-25.

73. Nishiyama A, Wakasugi N, Kirikae T, et al. Risk factors for SARS infection within hospitals in Hanoi, Vietnam. Jpn J Infect Dis 2008;61:388-390.

74. Raboud J, Shigayeva A, McGeer A, et al. Risk factors for SARS transmission from patients requiring intubation: a multicentre investigation in Toronto, Canada. PLoS One 2010;5(5):e10717.

75. Reynolds MG, Anh BH, Thu VH, et al. Factors associated with nosocomial SARS-CoV transmission among healthcare workers in Hanoi, Vietnam, 2003. BMC Public Health 2006;6:207.

76. Hastings DL, Tokars JI, Abdel Aziz IZAM, et al. Outbreak of Middle East Respiratory Syndrome at a tertiary care hospital. Emerg Infect Dis 2016;22:794-801.

77. Alraddadi BM, Al-Salmi HS, Jacobs-Slifka K, et al. Risk factors for Middle East respiratory syndrome coronavirus infection among healthcare personnel. Emerg Infect Dis 2016;22:1915-1920.

78. Kim CJ, Choi WS, Jung Y, et al. Surveillance of the Middle East respiratory syndrome (MERS) coronavirus (CoV) infection in healthcare workers after contact with confirmed MERS patients: incidence and risk factors of MERS-CoV seropositivity. Clin Microbiol Infect 2016;22:880-886.

79. Bridges CB, Katz JM, Seto WH, et al. Risk of influenza A (H5N1) infection among health care workers exposed to patients with influenza A (H5N1), Hong Kong. J Infect Dis 2000;181:344-348.

80. Viswanathan M, Ansari MT, Berkman ND, et al. Assessing the risk of bias of individual studies in systematic reviews of health care interventions. agency for healthcare research and quality methods guide for comparative effectiveness reviews. AHRQ Publication No. 12-EHC047-EF. https:// pubmed.ncbi.nlm.nih.gov/22479713/. Accessed January 2021.

81. Alraddadi BM, Al-Salmi HS, Jacobs-Slifka K, et al. Risk factors for middle east respiratory syndrome coronavirus infection among healthcare personnel. Emerg Infect Dis 2016;22:1915-1920.

82. Chen MIC, Leo Y-S, Ang BSP, Heng B-H, Choo P. The outbreak of SARS at Tan Tock Seng Hospital-relating epidemiology to control. Ann Acad Med Singapore 2006;35:317-325.

83. Ho KY, Singh KS, Habib AG, et al. Mild illness associated with severe acute respiratory syndrome coronavirus infection: lessons from a prospective seroepidemiologic study of health-care workers in a teaching hospital in Singapore. J Infect Dis 2004;189:642-647.

84. Hudson B, Toop L, Mangin D, Brunton C, Jennings L, Fletcher L. Pandemic influenza $\mathrm{A}(\mathrm{H} 1 \mathrm{~N} 1)$ pdm09: risk of infection in primary healthcare workers. Br J Gen Pract 2013;63(611):e416-e422.

85. Elkholy AA, Grant R, Assiri A, Elhakim M, Malik MR, Van Kerkhove MD. MERS-CoV infection among healthcare workers and risk factors for death: retrospective analysis of all laboratory-confirmed cases reported to WHO from 2012 to 2 June 2018. J Infect Public Health 2020;13:418-422.

86. Houghton C, Meskell P, Delaney $\mathrm{H}$, et al. Barriers and facilitators to healthcare workers' adherence with infection prevention and control
(IPC) guidelines for respiratory infectious diseases: a rapid qualitative evidence synthesis. Cochrane Database Syst Rev 2020;4(4):CD013582.

87. Ellingson K, Haas JP, Aiello AE, et al. Strategies to prevent healthcareassociated infections through hand hygiene. Infect Control Hosp Epidemiol 2014;35:937-960.

88. Tran K, Cimon K, Severn M, Pessoa-Silva CL, Conly J. Aerosol-generating procedures and risk of transmission of acute respiratory infections to healthcare workers: a systematic review. PLoS One 2012;7(4):e35797.

89. MacIntyre CR, Chughtai AA. Face masks for the prevention of infection in healthcare and community settings. BMJ 2015;350:h694.

90. Verbeek JH, Rajamaki B, Ijaz S, et al. Personal protective equipment for preventing highly infectious diseases due to exposure to contaminated body fluids in healthcare staff. Cochrane Database Syst Rev 2020;5:CD011621.

91. Chou R, Dana T, Buckley DI, Selph S, Fu R, Totten AM. Epidemiology of and risk factors for coronavirus infection in healthcare workers. Ann Intern Med 2020;173:120-136.

92. Chou R, Dana T, Jungbauer R, Weeks C, McDonagh MS. Masks for prevention of respiratory virus infections, including SARS-CoV-2, in health care and community settings: a living rapid review. Ann Intern Med 2020;173:542-555.

93. Rational use of personal protective equipment for coronavirus disease (COVID-19) and considerations during severe shortages: interim guidance, 6 April 2020. World Health Organization website. https://www.who.int/ publications/i/item/rational-use-of-personal-protective-equipmentfor-coronavirus-disease-(covid-19)-and-considerations-during-severeshortages. Published 2020. Accessed January 2021.

94. Adlhoch C, Cenciarelli O, Chiossi S, Handzlik M, Ndirangu M, Palm D. Guidance for wearing and removing personal protective equipment in healthcare settings for the care of patients with suspected or confirmed COVID-19. European Centers for Disease Control website. https://www.ecdc.europa.eu/ en/publications-data/guidance-wearing-and-removing-personal-protectiveequipment-healthcare-settings. Published 2020. Accessed January 2021.

95. Interim infection prevention and control recommendations for patients with suspected or confirmed coronavirus disease 2019 (COVID-19) in healthcare settings. Center for Disease Control and Prevention website. https://www.cdc. gov/coronavirus/2019-ncov/hcp/infection-control-recommendations. html. Published 2020. Accessed January 2021.

96. Chughtai AA, Seale H, Islam MS, Owais M, Macintyre CR. Policies on the use of respiratory protection for hospital health workers to protect from coronavirus disease (COVID-19). Int J Nurs Stud 2020;105:103567.

97. Bartoszko JJ, Farooqi MAM, Alhazzani W, Loeb M. Medical masks vs N95 respirators for preventing COVID-19 in healthcare workers: a systematic review and meta-analysis of randomized trials. Influenza Other Respi Virus 2020;14:365-373.

98. Long Y, Hu T, Liu L, et al. Effectiveness of N95 respirators versus surgical masks against influenza: a systematic review and meta-analysis. J Evid Based Med 2020;13:93-101.

99. SARS basics fact sheet. Centers for Disease Control and Prevention website. https://www.cdc.gov/sars/about/fs-sars.html. Published 2017. Accessed November 19, 2020.

100. Coronavirus disease (COVID-19) pandemic. World Health Organization website. https:/www.who.int/emergencies/diseases/novel-coronavirus2019. Published 2020. Accessed November 19, 2020.

101. Cook TM. Risk to health from COVID-19 for anaesthetists and intensivists-a narrative review. Anaesthesia 2020;75:1494-1508.

102. Pan D, Sze S, Minhas JS, et al. The impact of ethnicity on clinical outcomes in COVID-19: a systematic review. EClinicalMedicine 2020. doi: 10.1016/ j.eclinm.2020.100404.

103. Phan LT, Maita D, Mortiz DC, et al. Personal protective equipment doffing practices of healthcare workers. J Occup Environ Hyg 2019;16:575-581.

104. Wee LE, Sim XYJ, Conceicao EP, et al. Containment of COVID-19 cases among healthcare workers: the role of surveillance, early detection, and outbreak management. Infect Control Hosp Epidemiol 2020;41:765-771.

105. Bartoszko JJ, Farooqi MAM, Alhazzani W, Loeb M. Medical masks vs N95 respirators for preventing COVID-19 in healthcare workers a systematic review and meta-analysis of randomized trials. Influ Other Respir Virus 2020;04:4. 